\title{
Experimental Study of Boiling Heat Transfer and Pressure Drop of R32 inside Horizontal Multiport Tube with Circular Minichannels*
}

\begin{abstract}
Hikaru Eda** Daisuke Jige***
Norihiro Inoue $* * *$

This study experimentally investigated the boiling flow heat transfer and two-phase frictional pressure drop characteristics of the refrigerant R32 in a horizontal multiport tube with circular minichannels. The boiling heat transfer coefficients and two-phase pressure drops were measured at a saturation temperature of $15^{\circ} \mathrm{C}$ for mass velocities that ranged from 50 to $400 \mathrm{kgm}^{-2} \mathrm{~s}^{-1}$ and heat fluxes that ranged from 5 to $40 \mathrm{kWm}^{-2}$. The effects of mass velocity, heat flux, and vapor quality on the boiling heat transfer characteristics were clarified. The measured boiling heat transfer coefficients and two-phase frictional pressure drops were compared with previous correlations. Under the low mass velocity and low heat flux conditions, the boiling heat transfer characteristics differed from the previous correlations for conventional large diameter tubes. The two-phase frictional pressure drops were in good agreement with previous correlation, except for the mass velocity of $50 \mathrm{kgm}^{-2} \mathrm{~s}^{-1}$.
\end{abstract}

\section{Introduction}

Material and energy saving is one of the most critical issues today. From this view point, it is necessary to develop high-performance compact heat exchangers using minichannels with hydraulic diameters less than $1 \mathrm{~mm}$. However, the boiling heat transfer and flow characteristics in minichannels are different from those in conventional large-diameter tubes because the surface tension effect increases with decreasing channel size.

Few studies have been conducted on the flow boiling heat transfer and pressure drop in multiport tubes with minichannels and a hydraulic diameter less than $1 \mathrm{~mm}$. Tanaka et al. ${ }^{[1]}$ investigated the flow pattern and boiling heat transfer characteristics of R1234yf in a multiport tube with rectangular minichannels that had a hydraulic diameter of $0.9 \mathrm{~mm}$, and the results were compared to those obtained with circular minichannels that had a similar hydraulic diameter. Jige et al. [2] investigated the pressure drop and boiling heat transfer characteristics of R32 in multiport tubes

\footnotetext{
*Received October 23, 2017

** Graduate School of Marine Science and Technology,

Tokyo University of Marine Science and Technology

**** Tokyo University of Marine Science and Technology
}

with circular and triangular minichannels with hydraulic diameters of 0.52 and $0.38 \mathrm{~mm}$, respectively. However, little is known about the boiling heat transfer and frictional pressure drop characteristics of the refrigerant R32 in horizontal multiport tubes with circular minichannels.

This study experimentally investigated the boiling heat transfer and pressure drop characteristics of R32 in a horizontal multiport tube with circular minichannels. The effects of mass velocity, heat flux, and vapor quality on the boiling heat transfer and pressure drop characteristics were clarified.

\section{Experimental Apparatus and Method}

Figure 1 shows a schematic of the experimental apparatus used in this study. The test loop consisted of a magnetic gear pump, a water heat exchanger, an electric pre-heater, a test section, a condenser using a brazed plate heat exchanger, a liquid receiver, and a sub-cooler. The liquid refrigerant discharged from the gear pump flowed into the water heat exchanger and electric pre-heater through a Coriolis mass flow meter. The electric pre-heater heated the test refrigerant to obtain the desired vapor quality at the inlet of the test section. 
The liquid refrigerant returned to the pump by flowing through the condenser, the liquid receiver, and the sub-cooler. The refrigerant mass flow rate was mainly controlled by the flow regulating valves of the main and bypass loops.

Figure 2 shows a schematic of the test section. The test multiport tube was heated by electric sheet heaters attached to the upper and lower surfaces of the test tube. Homogeneous copper plates and heat conductive sheets were inserted between the electric heater and the test multiport tube to make the heat flux in the heating region uniform. The tube wall temperatures were measured using K-type thermocouples attached to the test tube wall at prescribed positions with $25 \mathrm{~mm}$ interval length. The refrigerant pressures in the pressure ports at the inlet and outlet of the test multiport tube were measured using absolute and differential pressure transducers.

Figure 3 shows a photograph of cross sectional view of the test multiport tube with circular

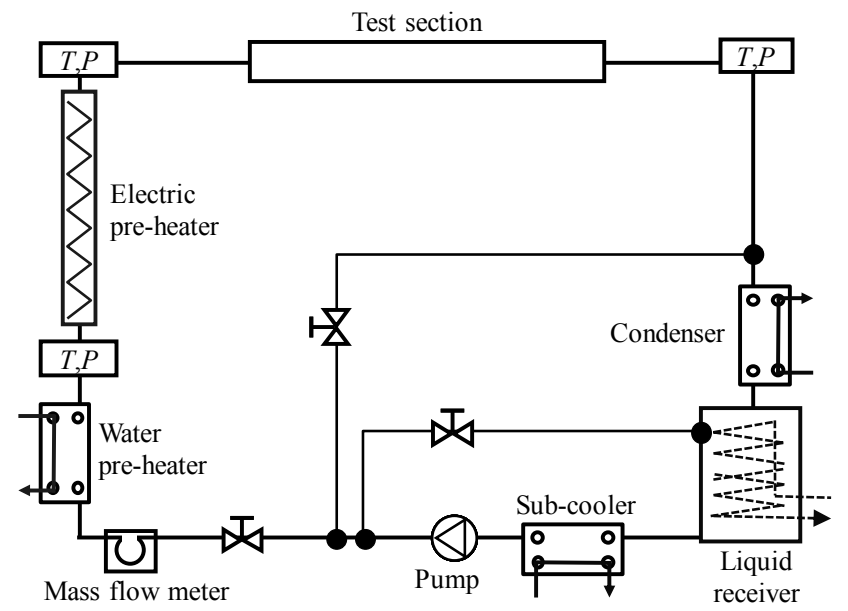

Fig. 1 Schematic of the test loop

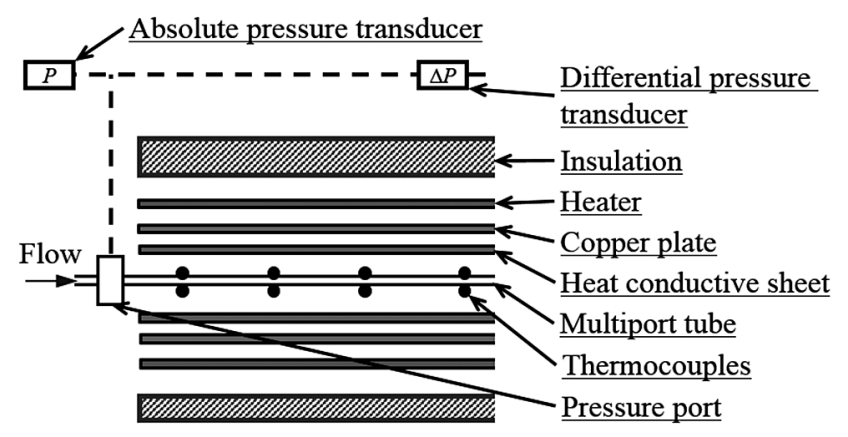

Fig. 2 Schematic view of the test section minichannels. Table 1 shows the detailed dimensions of the test multiport tube. The test tube, made of aluminum alloy, had 12 circular minichannels. The average hydraulic diameter of the test multiport tube was $0.81 \mathrm{~mm}$. The hydraulic diameter was calculated as follows:

$$
d_{\mathrm{h}}=4 A / S
$$

where $A$ and $S$ are the total cross section area and wetted perimeter length of the test tube, respectively. The effective heat transfer length of the test tube was $300 \mathrm{~mm}$.

The experiments were carried out using R32 as a test fluid. The mass velocities ranged from 50 to 400 $\mathrm{kgm}^{-2} \mathrm{~s}^{-1}$, and the heat fluxes ranged from 5 to 40 $\mathrm{kWm}^{-2}$. For all experiments, the saturation temperature was $15{ }^{\circ} \mathrm{C}$. The thermal-properties of R32 were calculated using NIST Refprop [3]. The uncertainties of the measured parameters in this experiment are given in Table 2.

\section{Data Reduction}

The specific enthalpy at the inlet of the test section was calculated using the mass flow rate of test refrigerant, heat transfer rate, and heat loss in the electric pre-heater. The distributions of the pressure and specific enthalpy of the test refrigerant in the test section were calculated by combining the energy and momentum balance equations. The local heat transfer coefficient, $\alpha$ was calculated as follows:

$$
\alpha=\frac{q}{T_{\mathrm{wi}}-T_{\mathrm{s}}}
$$

where $q$ is the heat flux based actual inner heat transfer area, $T_{\text {wi }}$ is the inner wall temperature, and $T_{\mathrm{s}}$ is the refrigerant saturation temperature. The inner wall temperature was calculated from the measured outer wall temperature using the one-dimensional equation of heat conduction. The mean uncertainty of the boiling heat transfer coefficient was estimated to be within $\pm 10 \%$ for most of the data. The maximum uncertainty occurred under the conditions of low heat flux, high 


\section{$\bullet \bullet \bullet \bullet \bullet \bullet \bullet \bullet \bullet \bullet \bullet \bullet$}

Fig. 3 Schematic view of the test multiport tube

Table 1 Details of the test multiport tube

\begin{tabular}{c|c}
\hline Channel number & 12 \\
\hline Tube width & $16.0 \mathrm{~mm}$ \\
\hline Tube thickness & $1.56 \mathrm{~mm}$ \\
\hline Wall thickness & $0.37 \mathrm{~mm}$ \\
\hline Hydraulic diameter & $0.81 \mathrm{~mm}$ \\
\hline
\end{tabular}

Table 2 Uncertainties of measured parameters

\begin{tabular}{l|c}
\hline Refrigerant temperature & $\pm 0.05 \mathrm{~K}$ \\
\hline Tube wall temperature & $\pm 0.1 \mathrm{~K}$ \\
\hline Absolute pressure & $\pm 1.2 \mathrm{kPa}$ \\
\hline Pressure difference & $\pm 0.04 \mathrm{kPa}$ \\
\hline Refrigerant mass flow rate & $\pm 0.72 \mathrm{gmin}^{-1}$ \\
\hline
\end{tabular}

vapor quality, and highest mass velocity, and it was estimated to be $\pm 37 \%$.

The pressure drops in the test section between the pressure ports at the inlet and outlet of the test section were measured under boiling flow conditions. The frictional pressure drop $\Delta P_{\mathrm{F}}$ was calculated as follows:

$\Delta P_{\mathrm{F}}=\Delta P_{\text {mes }}-\Delta P_{\mathrm{A}}-\Delta P_{\mathrm{E}}$

where $\Delta P_{\text {mes }}$ is the measured pressure drop, $\Delta P_{\mathrm{A}}$ is the acceleration pressure drop associated with the vapor quality change in the measuring section, and $\Delta P_{\mathrm{E}}$ is the pressure loss due to the abrupt contraction and expansion at the inlet and outlet of the test section. In this study, $\Delta P_{\mathrm{E}}$ was estimated using equations described in the book of Collier and Thome ${ }^{[4]}$. The uncertainty of the measured pressure drop was estimated to be $\pm 0.2-6.8 \%$ under all experimental conditions.

\section{Results and Discussion}

\subsection{Predicted Flow Pattern}

Figure 4 shows the predicted flow patterns for the experimental conditions when the flow pattern map

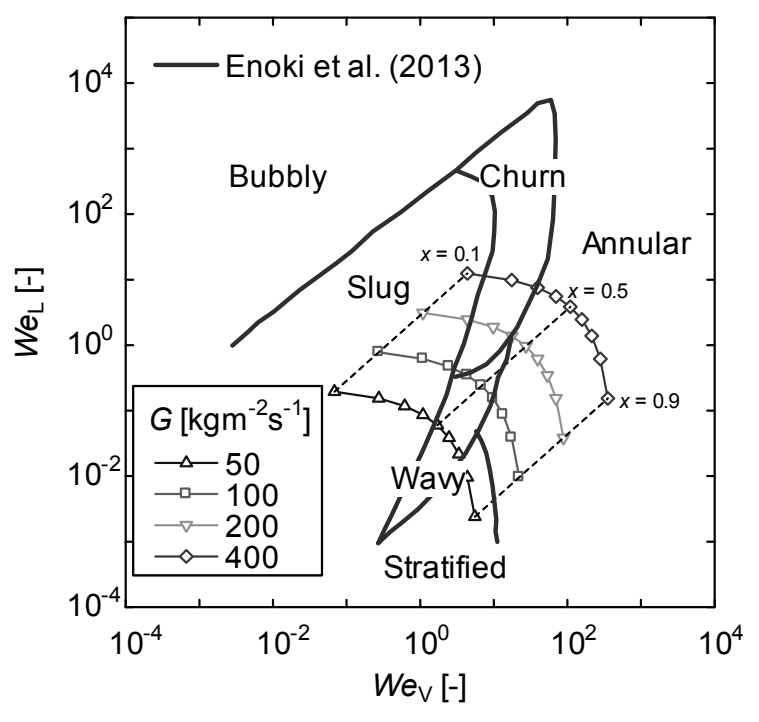

Fig. 4 Predicted flow pattern for experimental conditions with the flow pattern map of Enoki et al.

proposed by Enoki et al.[5] was used. This flow pattern map was proposed based on the observations in a circular horizontal single channel with a diameter of $1.03 \mathrm{~mm}$. The parameters for the horizontal and vertical axes in Figure 4 were calculated as follows:

$$
\begin{aligned}
& W e_{\mathrm{V}}=G^{2} x^{2} d_{\mathrm{h}} /\left(\rho_{\mathrm{V}} \sigma\right) \\
& W e_{\mathrm{L}}=G^{2}(1-x)^{2} d_{\mathrm{h}} /\left(\rho_{\mathrm{L}} \sigma\right)
\end{aligned}
$$

where $W e v$ and We are Weber numbers of vapor and liquid phases, respectively. Enoki et al.[5] divided the flow patterns of R410A in a circular horizontal tube, including slug, wavy, stratified, churn, and annular flows. In the case of the test multiport tube, it can be inferred that slug flow was observed at low mass velocities and low vapor qualities, and that annular flow was observed at high mass velocities and high vapor qualities.

\subsection{Boiling Heat Transfer}

Figure 5 shows the boiling heat transfer coefficient in the test multiport tube with circular minichannels with a saturation temperature of $15{ }^{\circ} \mathrm{C}$. The vapor quality at the inlet of the test section was changed to measure the boiling heat transfer coefficient over a wide vapor quality range. 
Under a high mass velocity condition, the boiling heat transfer coefficient increased with increasing mass velocity and vapor quality owing to the increment in the forced convective heat transfer. The boiling heat transfer coefficient increased with increasing heat flux owing to increased nucleate boiling in the higher mass velocities $(G>100$ $\left.\mathrm{kgm}^{-2} \mathrm{~s}^{-1}\right)$. However, the boiling heat transfer coefficient decreased with increasing heat flux at a mass velocity of $50 \mathrm{kgm}^{-2} \mathrm{~s}^{-1}$. The effect of heat flux on the boiling heat transfer characteristic in multiport tube with circular minichannels differed from that observed in conventional large diameter circular tubes. It was assumed that this boiling heat transfer characteristic was related to the flow pattern. The flow pattern at a low mass velocity and low vapor quality was slug flow according to the flow pattern map, as shown in Fig. 4. Therefore, the boiling heat transfer coefficient decreased with increasing heat flux because the thin liquid film formed around the elongated babble dried under the low mass velocity and high heat flux condition.

Figure 6 shows the relationship between the heat transfer coefficient $\alpha$ and the heat flux $q$ at a vapor quality of 0.2 . The correlation proposed by
Jung et al. ${ }^{[6]}$ for the pool boiling heat transfer is also shown in this figure. The measured heat transfer coefficients were in good agreement with Jung et al.'s correlation under the higher heat flux conditions. On the other hand, the values of the heat transfer coefficient under the lowest heat flux condition $\left(q=5 \mathrm{kWm}^{-2}\right)$ were higher than those at the higher heat flux conditions and the predicted values calculated by Jung et al.'s correlation. We speculated that the thin liquid film that formed around the vapor plug enhanced the heat transfer under a lower heat flux condition.

Figure 7 shows the relationship between $\alpha / \alpha_{\mathrm{L}}$ and the Lockhart-Martinelli parameter $1 / X_{\mathrm{tt}}$ at a heat flux of $5 \mathrm{kWm}^{-2}$ and mass velocity of 400 $\mathrm{kgm}^{-2} \mathrm{~S}^{-1}$. The heat transfer coefficient of the liquid phase $\alpha_{\mathrm{L}}$ and Lockhart-Martinelli parameter $X_{\mathrm{tt}}$ were calculated by

$$
\begin{aligned}
& \alpha_{\mathrm{L}}=\frac{\lambda_{\mathrm{L}}}{d_{\mathrm{h}}} 0.023\left[\frac{G(1-x) d_{\mathrm{h}}}{\mu_{\mathrm{L}}}\right]^{0.8} \operatorname{Pr}_{\mathrm{L}}^{0.4} \\
& X_{\mathrm{tt}}=\left(\frac{1-x}{x}\right)^{0.9}\left(\frac{\rho_{\mathrm{V}}}{\rho_{\mathrm{L}}}\right)^{0.5}\left(\frac{\mu_{\mathrm{L}}}{\mu_{\mathrm{V}}}\right)^{0.1}
\end{aligned}
$$
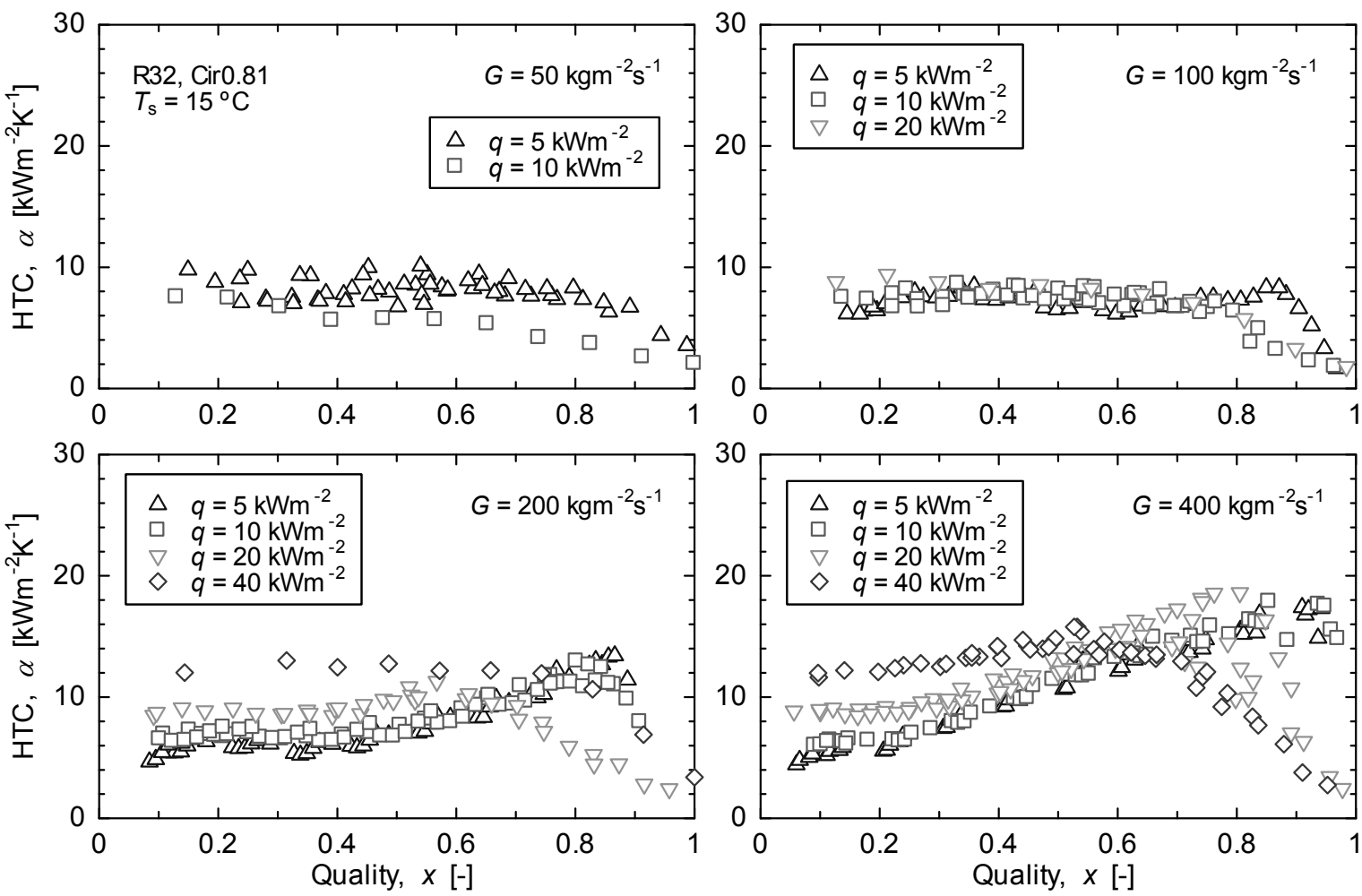

Fig. 5 Boiling heat transfer coefficient of R32 in the multiport tube with circular minichannels 


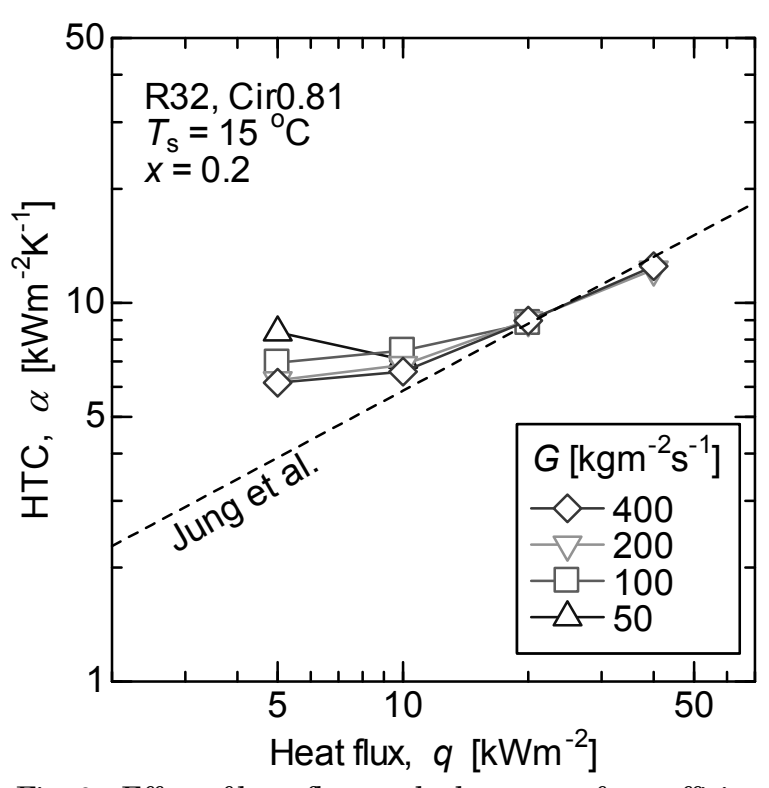

Fig. 6 Effect of heat flux on the heat transfer coefficient

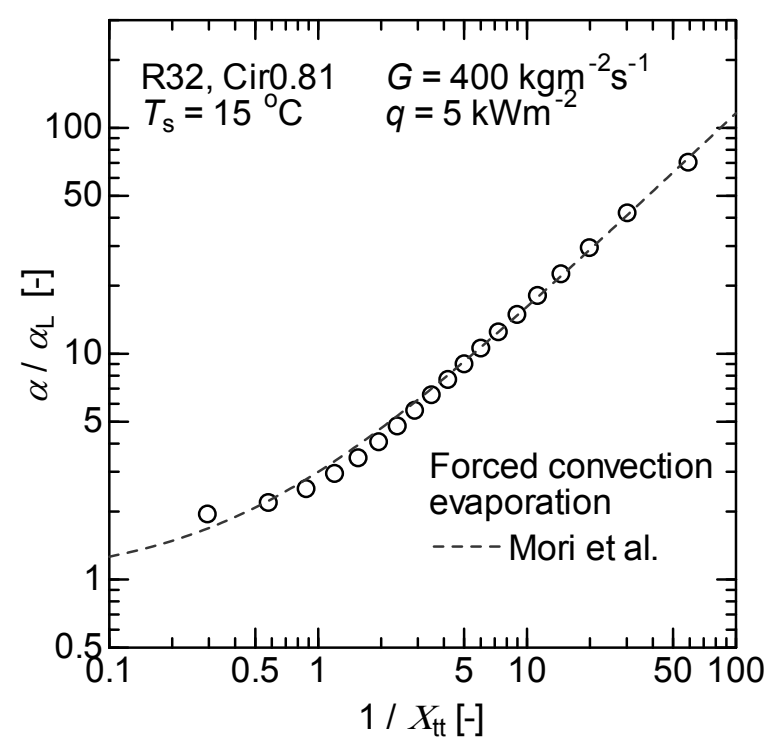

Fig. 7 Relationship between $\alpha / \alpha_{\mathrm{L}}$ and $1 / X_{\mathrm{tt}}$

The forced convection evaporation term of the Mori et al. ${ }^{[7]}$ correlation based on conventional circular tubes is also shown in Fig. 7. The measured value was in good agreement with the calculated value. Therefore, no difference in heat transfer characteristics between a conventional circular tube and the multiport tube with circular minichannels was observed under the forced convection dominant condition.

The multiport tube is therefore expected to enhance the boiling heat transfer more than the conventional circular tubes under conditions of lower mass velocity and lower heat flux.

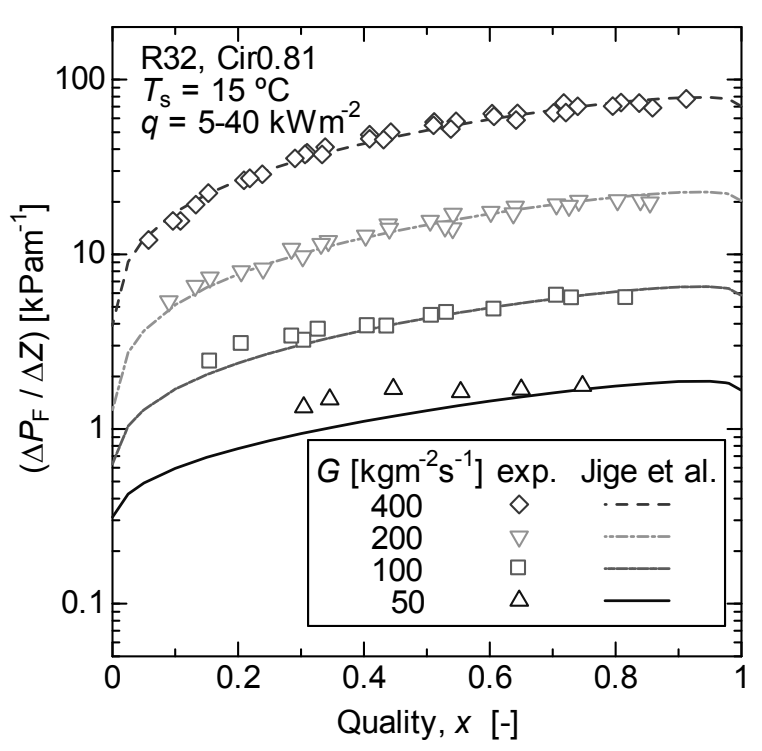

Fig. 8 Relationship between frictional pressure drop and quality for the boiling flow

\subsection{Pressure Drop}

Figure 8 shows the frictional pressure drop in the multiport tube for the boiling flow at heat flux of $5-40 \mathrm{kWm}^{-2}$ and saturation temperature of $15{ }^{\circ} \mathrm{C}$. The frictional pressure drop increased with increasing vapor quality and mass velocity owing to the increase in the vapor shear stress. In addition, a difference in pressure drop was not observed for heat fluxes that ranged from 5 to $40 \mathrm{kWm}^{-2}$. Figure 8 also shows the comparison between the measured frictional pressure drop and the predicted values calculated by the Jige et al. ${ }^{[8]}$ correlation. At higher mass velocities $\left(G>100 \mathrm{kgm}^{-2} \mathrm{~s}^{-1}\right)$, this correlation was in good agreement with the measured data of the multiport tube with circular minichannels. However, this correlation underpredicted the measured data at a mass velocity of $50 \mathrm{kgm}^{-2} \mathrm{~s}^{-1}$.

\section{Conclusions}

This study experimentally investigated the boiling heat transfer and pressure drop characteristics of R32 in a horizontal multiport tube with circular minichannels. The main results are summarized as follows:

(1) The flow patterns suggested that slug flow occurred at low mass velocities and low vapor qualities, and that annular flow occurred at high mass velocities and high vapor qualities.

(2) The boiling heat transfer coefficient increased 
with increasing mass velocity and heat flux expect for $G=50 \mathrm{kgm}^{-2} \mathrm{~s}^{-1}$.

(3) The boiling heat transfer characteristics in the multiport tube under conditions dominated by nucleate boiling and forced convection evaporation were in good agreement with the previous correlations for conventional large diameter tubes. However, the heat transfer characteristics differed under the low mass velocity and low heat flux conditions.

(4) The measured frictional pressure drop was in good agreement with the predicted values calculated by the Jige et al. ${ }^{[8]}$ correlation, except for the mass velocity of $50 \mathrm{kgm}^{-2} \mathrm{~s}^{-1}$.

\section{References}

[1] "Characteristics of flow boiling heat transfer in rectangular minichannels", C. Tanaka, C. Dang and E. Hihara, Proc. of the $15^{\text {th }}$ International Heat Transfer Conference (Kyoto), IHTC15-9589, CD-ROM, (2014)

[2] "Effect of Channel Geometry on Boiling Heat Transfer and Pressure Drop of R32 Inside Horizontal Multiport Tube”, D. Jige, Y. Terashima, N. Inoue, S. Koyama, Proc. of the $24^{\text {th }}$ IIR International Congress of Refrigeration ICR2015 (Yokohama), 703, (2015)

[3] Reference fluid thermodynamic and transport properties-REFPROP, Version 9.0, E.W. Lemmon, M.L. Huber and M.O. McLinden, National Institute of Standards and Technology Standard Reference database 23, (2010)

[4] "Convective boiling and condensation, third ed.", J.G. Colleier, J.R. Thome, Oxford University Press, (1994)

[5] "Flow Pattern of the Vapor-Liquid Two-phase Flow in Small Tubes", K. Enoki, H. Mori, K. Miyata, and Y. Hamamoto, Trans. JSRAE, Vol.30 No.2, pp.155-167, (2013)

[6] "Nucleate boiling heat transfer coefficients of pure halogenated refrigerants", D. Jung, Y. Kim, Y. Ko and K. Song, Int. J. Refrigeration Vol.26, pp.240-248, (2003)
[7] "Reform of the Correlation for the Prediction of Heat Transfer Coefficient for Refrigerants Flowing in Horizontal Evaporator Tubes”, H. Mori, S. Yoshida, Y. Kakimoto and K. Ohishi, Trans. JSRAE, Vol.16, No.2, pp.177-187, (1999)

[8] "Condensation of refrigerants in a multiport tube with rectangular minichannels", D. Jige, N. Inoue, S. Koyama, Int. J. Refrigeration, Vol.67, pp.202-213, (2016)

\section{Acknowledgements}

This research was supported by JSPS KAKENHI Grant Number JP2588902 and UACJ Corporation. We would like to express our gratitude to them.

\section{Nomenclature}

$A \quad$ : cross section area $\left[\mathrm{m}^{2}\right]$

$d_{\mathrm{h}} \quad$ : hydraulic diameter $[\mathrm{m}]$

$G \quad$ : mass velocity $\left[\mathrm{kgm}^{-2} \mathrm{~s}^{-1}\right]$

$q$ : heat flux [Wm-2]

$Q \quad$ : heat transfer rate [W]

$S \quad$ : wetted perimeter length [m]

$T_{\mathrm{s}} \quad$ : refrigerant temperature $\left[{ }^{\circ} \mathrm{C}\right]$

$T_{\mathrm{w}} \quad$ : wall temperature $\left[{ }^{\circ} \mathrm{C}\right]$

$x \quad$ : vapor quality [-]

$\alpha \quad$ : heat transfer coefficient $\left[\mathrm{Wm}^{-2} \mathrm{~K}^{-1}\right]$

$X_{\mathrm{tt}}$ : Lockhart-Martinelli parameter [-]

$\Delta P_{\mathrm{A}}$ : acceleration pressure drop $[\mathrm{Pa}]$

$\Delta P_{\mathrm{E}}:$ pressure loss at inlet and outlet of tube $[\mathrm{Pa}]$

$\Delta P_{\mathrm{F}}$ : frictional pressure drop $[\mathrm{Pa}]$

$\Delta Z$ : length $[\mathrm{m}]$

subscript

cal : calculation

exp : experimental

L : liquid phase

mes : measurement

$\mathrm{V}$ : vapor phase 